\title{
Mecanización agrícola, empleo y migración en el norte de Tamaulipas
}

\author{
José Luis Contreras Valenzuela
}

\begin{abstract}
Resumen
El objetivo del presente trabajo es analizar el modelo de desarrollo agrícola recientemente adoptado en los distritos de riego del norte de Tamaulipas, y los efectos sobre el empleo y la migración de la población rural. Dicho análisis se efectuará a partir de dos premisas fundamentales: una de ellas es la internacionalización del proceso productivo que se manifiesta con la presencia de una nueva división internacional del trabajo y lo que en este ensayo es llamada economía campesina, que fue la fuente primaria de la acumulación de capital de la agricultura mexicana, la cual jugará un papel importante para la acumulación de capital de la agricultura de los Estados Unidos de América, mediante la oferta de fuerza de trabajo agrícola barata, permitiendo el desarrollo de la agricultura comercial, modelo que ahora se ha volcado sobre la economía campesina condenándola a su desaparición como forma de subsistencia de la población rural, a quien expulsa de sus unidades de producción mediante el acaparamiento y el rentismo.
\end{abstract}

Palabras clave: mecanización agrícola, desempleo, migración, proceso productivo, economía campesina, rentismo.

\begin{abstract}
The objective of this work is to analyze the model of agricultural development that was recently adapted to irrigation districts of the North of Tamaulipas, and the effects upon employment and migration of rural population. This analysis will be applied starting on two basic premises: the first one is the internationalization of a productive process that is expressed by a new division of the internationalization of work and what is called peasant economics in this essay. This was the primary source of capital accumulation from Mexican agriculture, which will play an important role in capital accumulation derived from agriculture of the United States, through offer of cheap agriculture labor force. This will allow the development of commercial agriculture as a model that has expanded over farm economics, thus condemning it to disappear as a means of subsistence for country people. People who have lived from agriculture for many years are being expelled from their production units through monopolizing and leasing land.
\end{abstract}

Keywords: agricultural mechanization, unemployment, migration, productive process, peasant economics, leasing. 


\title{
MECANIZACION AGRICOLA, EMPLEO Y MIGRACION EN EL NORTE DE TAMAULIPAS ${ }^{1}$
}

\author{
Por \\ José Luis Contreras Valenzuela
}

\section{INTRODUCCION}

El desemplco ha sido un fenómeno atávico en cl norte de Tamaulipas que se ha visto agravado por la presente crisis económica que se manifiesta más profundamente con las devaluaciones de 1982 . La condición fronteriza de esta región y la importancia económica de su producción agropecuaria, han producido efectos particularmente serios en el empleo de campesinos y jornaleros agrícolas. Esas condiciones y cstos efectos scrán analizados en cstc trabajo.

En México, la crisis ha golpcado más fucrtemente al sector agrícola, y dentro de este sector, a la llamada cconomía campesina, que agrupa a cjidatarios y minifundistas, que para su subsistencia requieren tanto de su propia unidad de producción, consistente en una pequeña parcela en donde producen algunos bienes alimenticios para autoconsumo, como del jornalero agrícola en las grandes y medianas unidades de agricultura comercial; es decir, la agricultura capitalista cuyo desarrollo está basado fundamentalmente en el trabajo asalariado. A diferencia de este tipo de agricultura, la economía campesina es una estructura orgánica que se desarrolla fundamentalmente, con base en trabajo familiar. 2

En la región fronteriza del norte de México, donde se concentran los grandes centros de producción agrícola mediante los cultivos de riego, predomina en términos generales una agricultura altamente desarrollada, que se antoja ser un modelo fotocopiado del norteamericano, tanto por el tipo de agricultores como por los niveles de mecanización que en ellos existe. Pero también en esta región coexisten a la par de esos grandes emporios agrícolas, nú-

1 El presente trabajo, forma parte de un estudio más amplio sobre la agricultura de riego en el norte de Tamaulipas, que se está desarrollando como un proyecto de investigación individual del autor con el apoyo del Colegio de la Frontera Norte.

2 Al respecto, existe una clara identificación de lo que se ha dado en denominar economía campesina. Para efectos del presente trabajo hemos considerado dentro de esta denominación a las unidades de producción pequeñas, tanto ejidales de pequeña propiedad, que por el tamaño de sus parcelas se desarrollan básicamente mediante el trabajo familiar y no utilizan trabajo asalariado. Otra de las características de las economías campesinas es que son principalmente unidades de autoabaste cimiento, y el ingreso fundamental de los campesinos que practican esta forma de agricultura proviene del jornaleo agricola más que de las utilidades que la unidad de producción le genere. En el trabajo La agricultura de riego en el norte de Tamaulipas, se dedica todo un capitulo a la consideración de las distintas corrientes teóricas que analizan este aspecto y trata de llegarse a una conclusión respecto a si este concepto puede ser aplicado a las unidades de producción del norte de Tamaulipas atendiendo a la caracterización que en el mismo trabajo de cllas se hace. 
cleos considerables de población que por las características de sus unidades de producción encajan en lo que en líneas anteriores hemos llamado economía campesina. Este es el caso de los distritos de riego del bajo río Bravo y bajo río San Juan del estado de Tamaulipas, ubicado en el noreste de México.

El presente trabajo tiene como objetivo fundamental, analizar el modelo de desarrollo agrícola recientemente adoptado en los distritos de riego del norte de Tamaulipas, y los efectos que éste ha tenido en el empleo y la migración de la población rural. Dicho análisis se efectuará a partir de dos premisas fundamentales: una de ellas, la internacionalización del proceso productivo que se manifiesta con la presencia de una nueva división internacional del trabajo y lo que en este ensayo hemos llamado economía campesina, que fuera fuente primaria de la acumulación de capital de la agricultura mexicana, y que además (refiriéndose a la economía campesina de la región fronteriza del norte de México), jugará un papel importante para la acumulación de capital de la agricultura de los Estados Unidos de América, mediante la oferta de fuerza de trabajo agrícola barata, permitiendo el desarrollo de la agricultura comercial, modelo que ahora se ha volcado sobre la economía campesina condenándola a su desaparición como forma de subsistencia de la población rural, a quien expulsa de sus unidades de producción mediante el acaparamiento y el rentismo.

La agricultura en el norte de Tamaulipas cobra una gran importancia tanto por su participación en el producto interno bruto a nivel estatal, como por la gran población que de una u otra manera se encuentra vinculada con esta actividad como fuente fundamental de sus ingresos. Si bien es cierto que en los últimos años la población ha disminuido considerablemente en términos absolutos, la actividad, medida a través de su participación en cl PIB estatal, no ha dejado de ser importante.

Esta región fue cuna de un gran emporio algodonero en el periodo inmediato posterior a la Segunda Guerra Mundial, como consecuencia del gran mercado que la fibra blanca tenía a nivel internacional, y en vías de cumplir con el papel que se les había asignado a los distritos de riego del norte del país desde su formación: el de ser exportadores de materia prima para la industria norteamericana. Este proceso, que en términos de algunos estudiosos del problema del desarrollo lo han caracterizado como un fenómeno coyuntural en el periodo mencionado, actualmente se ha esfumado.

Los planteamientos aquí presentados son el resultado de una investigación, apoyada por un lado, en una recopilación de información estadística obtenida en las fuentes receptoras de información; es decir, información publicada en documentos oficiales, así como el conocimiento físico de la región, que se efectuó durante el año de 1983. 
Asimismo, y con el propósito de buscar información de apoyo para el sostenimiento de alguna de nuestras afirmaciones, se recurrió a la obtención de información directa, misma que se logró de dos maneras. Una de ellas fue la realización de una encuesta que se llevó a cabo durante los meses de noviembre y diciembre de 1983 durante un lapso de 20 días, que consistió en levantamiento de 100 encuestas orientadas a conocer el origen y el destino de la migración del campo a la ciudad, así como el motivo de la misma. Para lograrlo, se definió un pequeño cuestionario que se aplicó a personas que transitaban por las carreteras de la región en dirección de alguna de las ciudades (Matamoros, Reynosa o Valle Hermoso). Estos casos fueron scleccionados al azar y se administraron regularmente durante los 20 días. Por otro lado, también se efectuaron una serie de entrevistas con pcrsonas involucradas con la actividad productiva agropecuaria, a través de lo cual se pudo obtener información que permitió un mejor conocimiento de la región en lo que al sector agropecuario se refiere, pudiéndose, además, conocer la opinión de estas personas que representaban - al momento de la realización del estudio- a los sectores privado, público y al llamado sector social.

Entre las entrevistas mencionadas, destacan las efectuadas con personal directivo de empresas gubernamentales o paraestatales como la Subdelegación Regional de Conasupo, la delegación de SECOFI, gerencia regional de BANRURAL, Aseguradora Nacional Agrícola y Ganadera, representación de la Secretaría de Agricultura y Recursos Hidráulicos Zona Nortc, las jefaturas de los distritos de riego de la región, jefatura de programa agrícola de la representación estatal de SARH (Zona Norte), y personal directivo del Centro de Investigaciones Agrícolas del Golfo Nortc (CIAGON).

La opinión del sector privado se obtuvo a través de la Asociación Regional Ganadera, la Asociación Regional de Agricultores, la Cámara de Comercio local - principalmente en Matamoros-, la asociación de horticultores en la región, y con algunos otros agricultores de la región.

La opinión del sector social campesino se obtuvo a través de la entrevista con el Comité Regional Campesino (CNC), con dirigentes campesinos de algunos grupos ejidales, y con estrevistas a pequeños campesinos y ejidatarios de la región.

\section{CARACTERISTICAS GENERALES DE LOS DISTRITOS DE RIEGO, BAJO RIO BRAVO Y BAJO RIO SAN JUAN}

Para el estado de Tamaulipas, la agricultura representa una de las principales actividades económicas. La superficie cultivada en el estado, asciende 1 millón 73 hectáreas, de las cuales $34 \%$ son de riego y $66 \%$ de temporal. 
Las principales fuentes de abastecimiento de agua para la agricultura de riego son el río Bravo y el río San Juan, ambos localizados en el norte del estado, conformando dos grandes distritos de riego denominados, bajo río Bravo y bajo río San Juan, ya que se benefician con aguas del río del cual llevan su nombre. ${ }^{3}$

Entre ambos distritos, bajo río Bravo (25) y bajo río San Juan (26), riegan una superficie de 300,000 ha, lo que representa el $83 \%$ del total de la superficie de riego en el estado.

El resto de la superficie de riego se localiza en la región centro y sur del estado, zona en que la actividad agrícola descansa básicamente en la agricultura de temporal.

El distrito de riego número 25 tiene como fuente de aprovechamiento las corrientes del bajo río San Juan, mismo que se realiza a través de los almacenamientos de la presa La Amistad, con una capacidad de 1,981 millones de $\mathrm{m}^{3}$ y la presa Falcon, con 1,413 millones de $\mathrm{m}^{3}$. Asimismo, el sistema de riego se auxilia con el establecimiento de cárcamos de bombeo para el aprovechamiento de las corrientes superficiales de ambos ríos.

Cabe mencionar que los datos de almacenamiento se refieren exclusivamente a los volúmenes correspondientes a México, ya que en ambas presas de almacenamiento se manejan aguas internacionales, cuyos volúmenes de almacenamiento son compartidos. Así tenemos que la capacidad total de la presa Falcon es de 3,414 millones de $\mathrm{m}^{3}$ y una capacidad útil de 3,095; la presa La Amistad tiene una capacidad total de 4,379 millones de $\mathrm{m}^{3}$ y una capacidad útil de 4,099, correspondiéndole a México 1,981 millones de $\mathrm{m}^{3}$ de la primera, y 1,413 millones de $\mathrm{m}^{3}$ de la segunda.

El sistema de riego del distrito de riego núm. 25 o también llamado bajo río Bravo, se complementa con una red de vasos reguladores llamados, $\mathrm{El} \mathrm{Cu-}$ lebrón, Villa Cárdenas, Palito Blanco 1, Palito Blanco 2 y Palito Blanco 3, con una capacidad de almacenamiento de 137.7 millones de $\mathrm{m}^{3}$ y con una capacidad útil de 121.1 millones de $\mathrm{m}^{3}$.

La superficie física beneficiada con este sistema de riego asciende aproximadamente a 200 mil hectáreas, con el manejo aproximado de un volumen de agua distribuida de 1,236.7 millones de $\mathrm{m}^{3}$.

${ }^{3}$ Los distritos de riego o distritos de grande irrigación en general, para efectos de su identificación, la Secretaría de Recursos Hidráulicos los distingue mediante una determinada nomenclatura denominando al distrito de riego del bajo río Bravo, también como distrito de riego núm. 25 , y el distrito del bajo río San Juan como distrito de riego núm. 26. En lo sucesivo en el desarrollo de este traba. jo nos referiremos a ellos mediante la nomenclatura. 
La superficie beneficiada con el riego de este distrito se localiza en los diversos municipios del norte del estado, distribuidos de la siguiente manera: Matamoros $42 \%$, Río Bravo 29\% Valle Hermoso $27 \%$, y Reynosa $1.3 \%$.

La otra región de agricultura de riego importante en el norte de Tamaulipas, es el distrito de riego número 26 , o también llamado bajo río San Juan, que en total beneficia una superficie física de aproximadamente $72 \mathrm{mil} \mathrm{hec-}$ táreas, y un área regable de 80 mil.

Los tipos de aprovechamiento son la presa Marte.R. Gómez, con una capacidad de almacenamiento de 936 millones de $\mathrm{m}^{3} \mathrm{y}$ un volumen utilizable de 550 millones de $\mathrm{m}^{3}$. Las aportaciones a esta presa de almacenamiento provienen del río San Juan. Dentro de este distrito se consideran unas $10 \mathrm{mil}$ hectáreas que se riegan mediante plantas de bombeo manejadas por particulares (unas 8,000 ha) y por la jefatura del distrito de riego (unas 2,000 ha) pero con aguas del río Bravo.

La distribución de la superficie beneficiada con este distrito de riego se da de la siguiente manera: Mier, 2.2\%; Miguel Alemán, 5.3\%; Camargo, $14.1 \%$; Díaz Ordaz, $14.0 \%$; Reynosa, $28.7 \%$;y Río Bravo, $35.6 \%$.

CUADRO No. 1 Tenencia de la tierra en los distritos de riego del norte de Tamaulipas.

\begin{tabular}{lrrrr}
\hline & \multicolumn{4}{c}{ AGRICULTORES Y SUPERFICIE } \\
CONCEPTO & \multicolumn{1}{c}{25} & $\mathbf{2 6}$ & $\mathbf{5 0}$ & \multicolumn{1}{c}{ Total } \\
\hline Núm. de peq. prop. & 2,451 & 3,654 & 134 & \multicolumn{1}{c}{6,239} \\
Superficie & 113,480 & 65,118 & 117,626 & 196,224 \\
Núm. de colonos & 2,426 & - & - & 2,426 \\
Superficie & 28,569 & - & - & 28,569 \\
Núm. de ejidatarios & 6,220 & 1,543 & 333 & 8,096 \\
Superficie & 58,661 & 13,868 & 5,463 & 77,992 \\
Total de agricultores & 11,097 & 5,197 & 476 & 16,761 \\
Total superficie & 200,710 & 78,968 & 23,089 & 302,785 \\
\hline
\end{tabular}

NOTA: Son las superficies y agricultores registrados.

FUENTE: Dirección General de Distritos de Riegoj Secretaría de Agricultura y Recursos Hidráulicos. 
Estos distritos de riego (el 25 y 26) en conjunto riegan una superficie mayor a 300 mil hectáreas, In que representa el $87 \%$ de la superficie regada en el estado. De ahí la importancia de que la agricultura que aquí se desarrolle tiene para la economía estatal, y que ésta sea el centro de atención al tratar de estudiar la agricultura de riego en la región. Cabe mencionar que por su extensión, esta región agrícola es una de las más importantes en México y en ella se genera aproximadamente el $20 \%$ de la producción de sorgo a nivel nacional.

Ambos distritos de riego fueron creados en el periodo de la Segunda Guerra Mundial, iniciando su operación el distrito de riego número 25 en el año de $1941, \mathrm{y}$ cl distrito númcro $26 \mathrm{cn} \mathrm{cl}$ año de 1943.

\section{MODIFICACION DE LOS PATRONES DE CULTIVO.}

Durante los años cincuenta en la región norte de Tamaulipas, las siembras del algodón cubrían aproximadamente cien mil hectáreas, que representaban las tres cuartas partes de la superficie total de riego. A principios de los sesenta la superficie dedicada al algodón en la región norte empieza a disminuir considerablemente, dándose, además, un proceso de traslación geográfica hacia el centro y sur del estado, donde empieza a cultivarse este producto en tierras de temporal.

No obstante, las superficies que de este cultivo se llegaron a sembrar en la región centro y sur del estado, no fueron mayores a las veinte mil hectáreas, lo que evidencia una caída real en su importancia, atendiendo a la superficie que al mismo se destinara.

Es precisamente durante los tiempos del florecimiento del cultivo de algodón (década de los cincuenta), en que surgen en la región grandes capitales que, con origen en la agricultura, empiezan a dedicarse a la comercialización de esta fibra y al proceso de industrialización primaria de la misma (despepitadoras).

Estos capitales posteriormente se extienden a otras ramas industriales y se trasladan al sector financiero, formando un grupo industrial y financiero que a nivel nacional llegó a cobrar una relevante importancia, tal es el caso del grupo Longoria. Asimismo, surgieron otros capitales que si bien llegaron a ser importantes en el marco regional, no llegaron a ser tanto como lo fue el grupo Longoria en el contexto de la nación.

El pcriodo de florecimiento del algodón se caracteriza también por un gran crecimiento de la población ocupada en el sector agrícola, ya que la recolección de éste requería de grandes masas de trabajadores. Esta característica - de ser intensiva en el uso de fuerza de trabajo-convirtió a las regiones 
quc se dedicaban a su cultivo, en polos de atracción de la población migrante del centro y sur del país, quienes encontraban ocupación temporal en los periodos de pizca. Así es como en los años cincuenta, periodo de auge algodonero en la región norte de Tamaulipas, inmigró hacia esta zona una gran cantidad de población, y algunos de los que llegaron se integraron a los centros urbanos de la región; otros más emigraban en forma temporal a Estados Unidos, ya que mediante el Convenio de Braceros podían trabajar en los campos agrícolas del sur de Texas también en forma temporal. ${ }^{4}$

En el transcurso de los años cincuenta, la superficie dedicada al cultivo del algodón en las tierras de riego en el norte del estado se va reduciendo, y con ello, la importancia que este cultivo representa en la agricultura regional. Entre las distintas causas que provocaban la disminución de las áreas dedicadas al cultivo del algodón se pueden mencionar la contracción del mercado del mismo y la consecuente disminución del precio de este producto en el mercado internacional. Este fenómeno coincidió, además, con el surgimiento y generalización de las fibras sintéticas derivadas del petróleo, que competían con las fibras derivadas del algodón desplazando fuertemente a estas últimas.

La caída del mercado y la disminución del precio del algodón trajeron como consecuencia que el nivel de la rentabilidad económica o margen de utilidad de este cultivo se contrajera, dejando de ser atractivo para el productor regional.

La disminución del precio y la caída del margen de ganancia en este cultivo, hacían incosteable su siembra en áreas de riego, que, obviamente, operaban con costos de producción más elevados que en áreas de temporal, por lo que su práctica se traslada a las zonas temporaleras del centro y sur del estado, que además de garantizar menores costos de producción, ofrecían condiciones de clima más favorables. A la vez que el cultivo de algodón se traslada a las zonas agrícolas temporaleras del centro y sur de la entidad, en los distritos agrícolas de riego del norte de Tamaulipas, las superficies hasta antes cubiertas por algodón empezaban a destinarse al cultivo del maíz.

Fue tan rápido este proceso de sustitución de cultivo de algodón por maíz, que para el año de 1960 el maíz cubría 49,678 hectáreas, lo que representaba el $60 \%$ de la superficie total de riego de la región, haciéndolo aparecer como el cultivo de mayor importancia en el norte del estado (cuadros 2 y 3).

La siembra del maíz era alentada por una política de precios e incentivos para su producción, a fin de detener las crecientes compras que de este

\footnotetext{
4 Bajo el programa de trabajadores migratorios temporales, o también conocido como Programa de Braceros, celebrado primeramente el 23 de julio de 1942, llegaron a aceptarse los mayores contingentes de trabajadores agrícolas durante el período 1951 a 1964.
} 
MECANIZACION AGRICOLA, EMPLEO Y MIGRACION

CUADRO 2. Características de la agricultura de riego en el norte de Tamaulipas.

Superficie sembrada de malz songo $y$ frijol

en los distritos de riego del norte de Tamaulipas

\begin{tabular}{rrrrrrrr} 
Años & Absoluto & Rel. & Absoluto & Rel. & Absoluto & Rel. & \multicolumn{1}{l}{ Total } \\
\hline 1960 & 67,015 & 68 & 26,913 & 27 & 4,133 & 4 & 98,061 \\
1961 & 88,465 & 57 & 60,990 & 39 & 5,847 & 4 & 155,302 \\
1962 & 94,880 & 70 & 39,650 & 29 & 1,380 & 1 & 135,910 \\
1963 & 47,932 & 47 & 52,983 & 52 & 180 & 1 & 101,095 \\
1964 & 159,863 & 60 & 106,301 & 40 & 2,350 & - & 268,514 \\
1965 & 209,569 & 72 & 79,544 & 27 & 1,070 & 1 & 290,183 \\
1966 & 145,874 & 44 & 184,905 & 56 & 1,590 & - & 332,429 \\
1967 & 126,540 & 44 & 159,891 & 56 & 1,559 & - & 287,990 \\
1968 & 125,556 & 43 & 161,863 & 56 & 3,220 & 1 & 290,639 \\
1969 & 166,129 & 51 & 158,438 & 48 & 3,833 & 1 & 328,400 \\
1970 & 133,603 & 44 & 172,968 & 56 & 218 & - & 306,789 \\
1971 & 157,280 & 50 & 157,601 & 58 & 1,023 & - & 315,904 \\
1972 & 139,392 & 41 & 199,382 & 58 & 2,564 & 1 & 341,335 \\
1973 & 134,275 & 36 & 231,530 & 63 & 3,402 & 1 & 369,177 \\
1974 & 138,665 & 38 & 195,568 & 54 & 30,964 & 8 & 365,197 \\
1975 & 107,439 & 30 & 225,004 & 64 & 21,558 & 6 & 354,001 \\
1976 & 147,703 & 40 & 216,916 & 59 & 4,952 & 1 & 369,971 \\
1977 & 198,085 & 57 & 143,374 & 42 & 3,733 & 1 & 345,192 \\
1978 & 146,915 & 47 & 151,822 & 49 & 10,915 & 4 & 309,652 \\
1979 & 125,372 & 43 & 151,377 & 50 & 10,239 & 5 & 289,988 \\
1980 & 200,589 & 56 & 129,334 & 36 & 24,967 & 8 & 359,013 \\
1981 & 138,083 & 38 & 176,906 & 49 & 34,587 & 13 & 363,172 \\
1982 & 201,918 & 54 & 125,430 & 34 & 35,715 & 12 & 370,769 \\
\hline & & & & & & &
\end{tabular}

FUENTE: Secretaría de Agricultura y Recursos Hidráulicos. Representación general zona norte. Jefatura de Programa Agrícola.

grano se venían haciendo en el extranjero. Dicha política de precios elevaba los niveles de rentabilidad económica del cultivo del maíz, haciéndolo a la vez más atractivo para los productores de la región, toda vez que el precio del algodón en el mercado internacional empezaba a declinar y su demanda a contraerse ante la aparición y generalización de las fibras sintéticas para la industria del vestido, que empezaban a cobrar vital importancia en esa época. Posteriormente, y a mediados de los sesentas, favorecido por la presencia de empresas trasnacionales que demandaban granos para el apoyo a la producción pecuaria, el sorgo figura como cultivo altamente rentable, de tal manera que, a finales de los sesenta empieza a cobrar superficies crecientes para su 
CUADRO 3. Características de la agricultura de riego en el norte de Tamaulipas. Participación porcentual de los cultivos principales en superficie sembrada y valor de producción 1960 - 1982.

\begin{tabular}{rcccccccr}
\hline & \multicolumn{2}{c}{ MAIZ } & \multicolumn{2}{c}{ SORGO } & \multicolumn{2}{c}{ FRIJOL } & \multicolumn{2}{c}{ OTROS } \\
Año & Superficie & Valor & Superficie & Valor & Superficie & Valor & Superficie & Valor \\
\hline 1960 & 68.3 & 69.7 & 27.4 & 29.4 & 4.2 & 0.7 & 0.9 & 0.1 \\
1965 & 72.2 & 72.2 & 25.8 & 27.7 & 0.4 & 0.1 & 1.6 & 0.0 \\
1970 & 43.5 & 48.2 & 56.3 & 51.8 & - & - & 2.0 & 0.0 \\
1971 & 49.6 & 46.4 & 47.8 & 51.8 & 1.3 & 0.1 & 1.3 & 1.7 \\
1972 & 39.6 & 53.3 & 57.2 & 38.5 & 1.0 & 0.8 & 2.2 & 7.4 \\
1973 & 38.4 & 37.9 & 55.7 & 52.3 & 1.3 & 0.6 & 4.6 & 9.2 \\
1974 & 37.1 & 36.2 & 50.6 & 50.5 & 8.9 & 6.9 & 3.4 & 6.4 \\
1975 & 32.5 & 24.4 & 56.0 & 60.2 & 8.9 & 3.8 & 2.6 & 11.6 \\
1976 & 39.9 & 40.4 & 55.8 & 49.8 & 2.2 & 0.8 & 2.1 & 9.0 \\
1977 & 57.8 & 58.6 & 37.6 & 35.5 & 2.0 & 0.3 & 2.6 & 5.6 \\
1978 & 48.1 & 50.6 & 43.4 & 40.2 & 4.2 & 2.9 & 4.3 & 6.3 \\
1979 & 44.8 & 52.0 & 47.5 & 39.9 & 4.4 & 2.7 & 3.3 & 5.4 \\
1980 & 53.0 & 54.2 & 33.0 & 34.8 & 10.3 & 3.6 & 3.7 & 7.4 \\
1981 & 37.1 & 53.0 & 47.3 & 36.6 & 11.6 & 6.2 & 4.0 & 4.2 \\
1982 & 53.2 & 66.1 & 32.8 & 27.1 & 11.5 & 4.6 & 2.5 & 2.2 \\
\hline
\end{tabular}

FUENTE: Elaborado con basc en el cuadro número 31 del apéndice estadístico. 
siembra en las tierras que antes se destinaban al maíz. Así tenemos que mientras para 1965 el $72 \%$ de la superficie total de riego en la región se destinaba al cultivo del maíz, el sorgo cubría el $26 \%$. Para 1970 , como puede observarse en el cuadro 1 , es notoria la importancia que el cultivo de sorgo cobra en la región, ya que a él se destina el $56 \%$ de la superficie total de riego, mientras que la superficie dedicada al maíz había bajado hasta $43 \%$ (cuadro $3)$.

Su importancia aumenta en los cinco años posteriores, llegando en 1965 a cubrir el $72 \%$ de la superficie total sembrada con 210,000 hectáreas. En ese período, el sorgo, cultivo de reciente expansión en la agricultura mexicana, también varía paralelamente al maíz, cobrando importancia en la región. Para esos años, la superficie de riego dedicada a su cultivo representaba el $27 \%$ aproximadamente.

La caída del algodón en el mercado internacional por un lado, aunada a la creciente necesidad de producir alimentos, jugaron un papel importante en el cambio de cultivos en la región. Este período de 1950 hasta 1965 puede caracterizarse como la sustitución del algodón y la creciente importancia del maíz como cultivo predominante, además de la aparición del sorgo alrededor de 1958 y su rápida expansión, llegándolo a convertir hasta 1965 en el segundo cultivo más importante de la región.

El crecimiento y rápida expansión del mercado de productos pecuarios derivados, a su vez del crecimiento de la población urbana en México, ha provocado un rápido crecimiento de la demanda de sorgo, ya que este grano es un insumo básico en la elaboración de alimentos balanceados para los diversos tipos de ganados, además de ser insumo básico para la producción avícola.

Este fenómeno nos explica la importancia cobrada por el sorgo en los años sesenta, a la vez que se convierte en factor explicativo para entender el proceso de sustitución del maíz por este grano, hecho que se inicia en la región norte de Tamaulipas a partir del año de 1965, cuando ocurre un rápido crecimiento en la superficie dedicada a este grano, y una brusca caída en la dedicada al maíz. Como puede observarse en la figura 1, el sorgo, que en el año de 1965 cubría el 25\% de la supcrficic de riego cultivada en la región, alcanza para 1970 el $57 \%$, mientras que, por el contrario, el maíz que para 1965 cubría el $72 \%$ de la misma superficie, cae en 1970 hasta el $43 \%$.

Los años comprendidos en el período 1970 a 1982 se caracterizan por registrar algunas variaciones importantes, pero con predominancia del sorgo como cultivo principal hasta el año de 1976 (figura 1). A partir de este año las variaciones son más frecuentes, y se observa que el maíz recupera su importancia frente al sorgo, ya que salvo los años 1979 y 1981, llegó a cubrir más del $50 \%$ de la superficie de riego sembrada. 
Este fenómeno, que podría llamarse competencia entre maíz y sorgo, encierra tras de sí una competencia entre la demanda de grano para consumo animal y la de grano para consumo humano. Las variaciones en la superficie de cada uno de estos productos, son reflejo de los incentivos que para la producción de cada uno de ellos existían. Los incentivos orientados a generar un incremento en la siembra del maíz son porporcionados por el Estado a través de una política de precios e insumos para la producción de este grano como medida tendiente a buscar la autosuficiencia en el renglón de alimentos. Por otro lado, los incentivos en la siembra y producción de sorgo los proporcionan las empresas trasnacionales integradas al complejo agroindustrial, productor de alimentos balanceadios.

En la figura 1, se puede observar una perfecta relación asimétrica en cuanto a superficies sembradas de sorgo y maíz.

Un tercer cultivo considerado en la gráfiça es el del frijol, que ha sido incluido con el propósito de explicar el estancamiento de la superficie de sorgo en los años 1973 a 1976, no obstante la caída de la superficie dedicada al maíz.

Durante los años 1973 hasta 1976, la siembra de frijol surge o cobra importancia en algunas regiones agrícolas del país, como reflejo del incremento en el precio de garantía de este producto, ocurrido durante esos años como respuesta del gobierno para incentivar la producción de este grano, ya que para esos años sus compras en el exterior eran bastante importantes. En este tiempo, dentro de la política oficial de promover el desarrollo rural definido por el presidente Echeverría, se dieron los primeros incrementos a los precios de garantía de los productos agrícolas, despues de casi 12 años de que se habían estancado (figura 2).

Para los años posteriores se denota un relativo estancamiento en la superficie dedicada al frijol, mientras que la del sorgo se incrementaba, situación que dura hasta el año de 1980 cuando las superficies dedicadas al maíz $y$ frijol se incrementan como consecuencia de los incentivos que para la producción de granos básicos para consumo humano, se hicieron a través del Sistema Alimentario Mexicano.

La creciente importancia del sorgo que se observa después del año de 1965 hasta 1976, nos explica el proceso de ganaderización de la agricultura, consecuencia - como lo explican algunos cstudiosos de la agricultura mexicana, entre ellos el propio David Barkin y Blanca Suárez-, de la modernización de la economía mexicana y del crecimiento de la población urbana en México. Se considera también factor explicativo del proceso de ganaderización de la agricultura, el hecho de que el sorgo es el insumo básico para la producción de alimentos balanceados para el ganado. Finalmente, las variaciones 


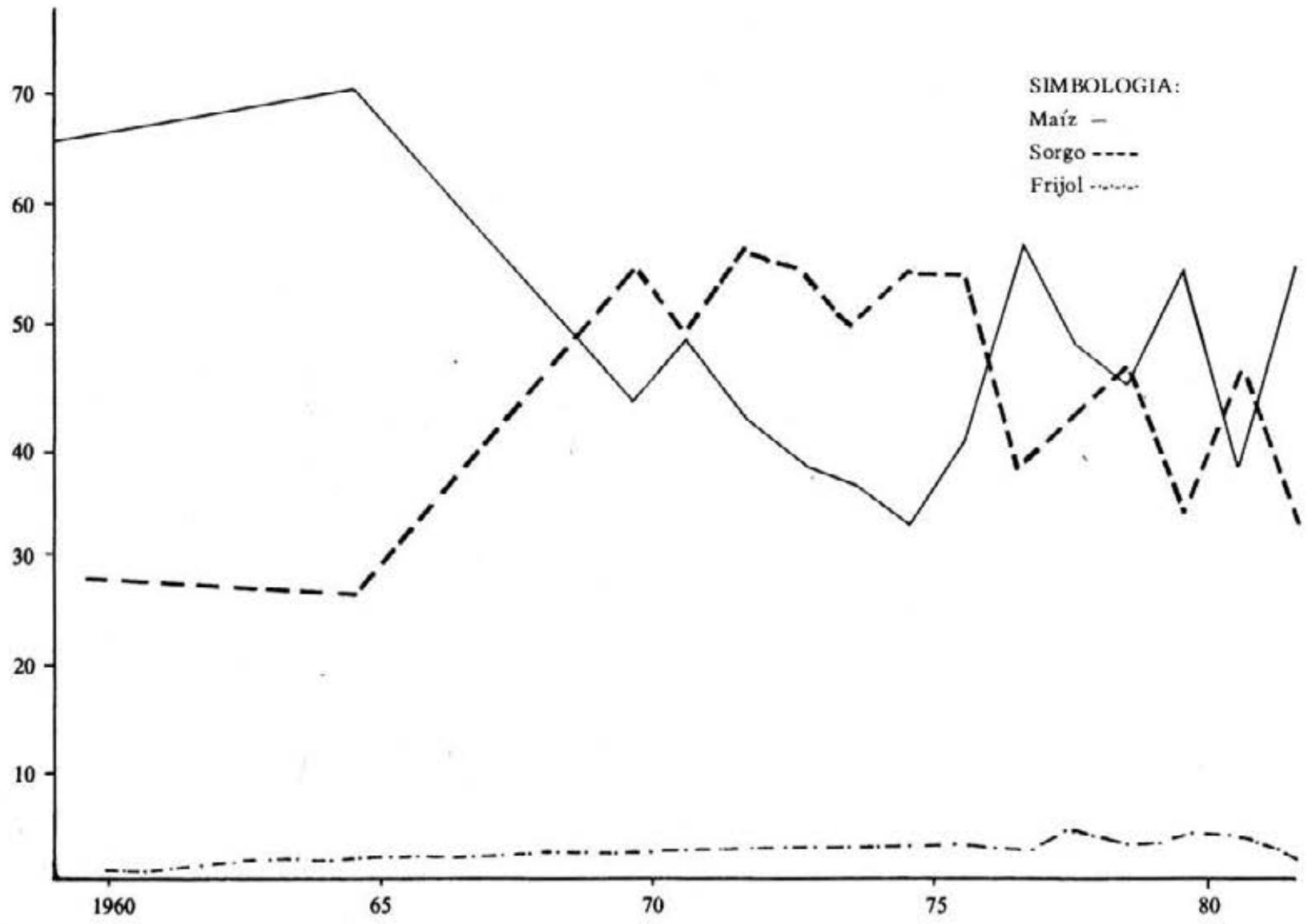

FIGURA 1. Distribución porcentual de la superficie sembrada por cultivos principales en los distritos de riego del norte de Tamaulipas $1960-1982$. 


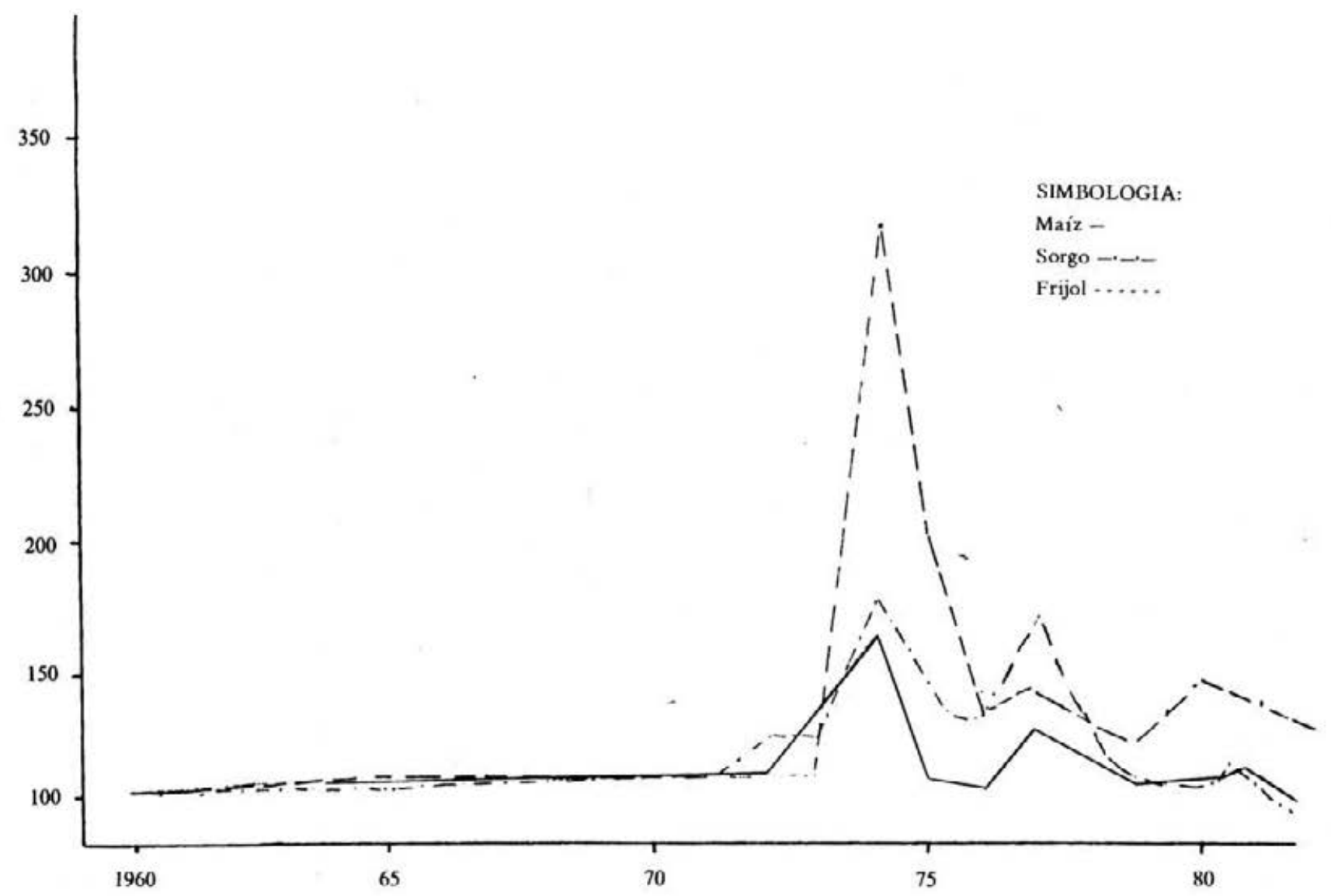

FIGURA 2. Indice de precios de garantía de frijol, maíz y sorgo. Precios constantes. 1960-100. 
que se observan entre las superficies dedicadas al sorgo y al maíz durante los años 1980 hasta 1982, nos sugieren pensar que el crecimiento de maíz se da como consecuencia de la implantación de las políticas de incentivos para la producción de este grano, definidas por el Sistema Alimentario Mexicano, mientras que el sorgo es promovido por las empresas dedicadas a la producción de alimentos balanceados para ganado.

Esto nos señala el alto grado de sensibilidad que la actividad agrícola regional tiene respecto de los precios e incentivos a la producción, en virtud de ser una agricultura comercial.

\section{MECANIZACION Y GENERÁCION DE EMPLEO.}

La aparición del sorgo, cultivo promovido por las transnacionales involucradas en la producción de alimentos balanceados, es un cultivo que por sus características requiere de un uso intensivo de capital, más que de mano de obra. Estc cambio en el patrón de cultivos ha provocado de por sí una agudización en el proceso de desplazamiento de mano de obra campesina, lo que ha afectado seriamente a los campesinos de pocos recursos, quienes poseen una pequeña unidad de producción agrícola que no les garantiza el sustento familiar y que tenían como fuente fundamental complementaria de ingreso $\mathrm{cl}$ jornaleo que realizaban en los campos agrícolas de la región, donde eran ocupados temporalmente.

Una idea un poco más clara de la dimensión del problema nos la dan las cifras presentadas en los cuadros 4 y 5 del apéndice estadístico, que nos muestran la capacidad de generación de jornales por hectárea de los cultivos considerados como principales en la región.

Mientras que en los años cincuenta el algodón generaba un promedio de 110 jornales aproximadamente por hectárea, el maíz (cultivo predominante en los sesenta) sólo generaba treinta y dos, y el sorgo, un promedio de 45 jornales por hectárea. Estos coeficientes de generación de jornales se dan cuando la recolección del maíz sc hace en forma manual y los trabajos de preparación de la ticrra, cultivos y otras tarcas de bencficio se hacen con maquinaria e implementos agrícolas "medianos", similares a los que se utilizan en otras regiones agrícolas e incluso en otros distritos de riego del norte del país. 5

\footnotetext{
5 En un apartado dedicado al análisis de las técnicas y métodos de cultivo del urabajo que actualmente viene desarrollando el autor de este documento titulado La agricultura de riego del norte de Ta. maulipas, se hace referencia a que los indices de mecanización de los distritos de riego del norte de Tamaulipas son más elevados que los del resto de los distritos de riego del norte del país. Este indi: ce ha sido medido a través del número de tractores y fuerza motriz (caballo de fuerza) por hectáreas.
} 
Pero cuando la pizca es mecánica, como es el caso actual del norte de Tamaulipas, donde todo el proceso se encuentra mecanizado y los trabajos de preparación de la tierra y cultivo se efectúan con equipo "demasiado grande" para el tamaño de las parcelas, los coeficientes de generación de jornales de cada uno de esos cultivos por hectárea se reducen a un veintidós y a un treinta y cuatro por ciento para el maíz y' el sorgo respectivamente. Es decir, al nivel actual de mecanización de la agricultura comercial de riego en el norte de Tamaulipas, los cultivos principales - maíz y sorgo-sólo generan 7.5 jornales por hectárea (cuadros 4 y 5 ).

Así tenemos, por ejemplo, que en los años cincuenta según se registra en las estadísticas del sector, se llegaron a sembrar más de doscientas mil hectáreas de algodón, misma superficie con la que se llegaron a generar en esos años más de veinte millones de jornales durante un ciclo agrícola. De estos jornales, casi un cuarenta por ciento se concentraba en un mes del año que era el periodo de pizca o recolección. En total, esa cantidad de jornales daba ocupación temporal a un número aproximado de ciento treinta mil personas, quienes podían laborar como jornaleros en la recolección de este producto (cuadro 6).

Por otra parte, durante los años sesentas, cuando en la región se llegaron a sembrar las más grandes superficies de maíz, y cuando los niveles de mecanización no eran tan elevados y la cosecha del mismo, en un alto porcentaje, sc efectuaba en forma manual, se llegaron a generar un promedio de 6.7 millones de jornales durante el año, de los cuales unos dos millones, es decir el $30 \%$ se concentraba en la época de pizca o recolección. Esto representaba una ocupación temporal para aproximadamente unos treinta mil campesinos o jornaleros agrícolas.

El sorgo, el cultivo más importante en los últimos diez años, como se mencionó con anterioridad, es el que menor capacidad de generación de jornales tiene; es decir, es un cultivo con uso intensivo en capital y baja intensidad en el uso de mano de obra. En el año de 1981, en que se sembraron aproximadamente 175,000 hectáreas de este grano, sólo se generó un millón trescientos mil jornales, lo que representó ocupación temporal para un promedio de siete mil trabajadores del campo.

Como puede observarse en el cuadro-resumen que se presenta con anterioridad durante el período de algodón 1950-1960 se generaba el número más alto de empleos. Si consideramos a esc período, como base para nuestras estimaciones, y asignamos a los empleos que en el mismo se generaban un valor de 100 , podríamos afirmar que en los períodos siguientes en que predominó el maíz (1960-1970), se registró una reducción en el empleo del $77 \%$; y en el período posterior (1970-1980), caracterizado por el predominio del sorgo como principal cultivo, la generación de empleo se reduce en $94.6 \%$. 
CUADRO 4. Jornales por hectáreas en cultivo de marz en los distritos de riego del norte de Tamaulipas.

\begin{tabular}{ccc}
\hline Concepto & $\begin{array}{c}1960-1966 \\
\text { Jornales por } \\
\text { hectárea }\end{array}$ & $\begin{array}{c}1980-1983 \\
\text { Jornales por } \\
\text { hectárea }\end{array}$ \\
\hline
\end{tabular}

Preparación de la tierra

Siembra

Labores de beneficio

TOTAL

NOTA: ") Corresponde a pizca manual; este concepto var ia dependiendo del rendimiento.

*) Corresponde a pizca mecánica.

FUENTE: Secretaría de Agricultura y Recursos Hidráulicos. Representación general en el estado de Tamaulipas, zona norte.

Jefatura de distrito de riego No. 25, bajo rio Bravo. Departamento de Estadística.

Cuadro 5. Jornales por hectáreas en cultivo de sorgo en los distritos de riego del norte de Tamaulipas.

\begin{tabular}{ccc}
\hline Concepto & $1960-1966$ & $1980-1983$ \\
& $\begin{array}{c}\text { Jornales por } \\
\text { hectárea }\end{array}$ & $\begin{array}{c}\text { Jornales por } \\
\text { hectárea }\end{array}$ \\
\hline
\end{tabular}

Preparación de la tierra

Siembra

0.5

0.2

Labores de beneficio

16.5

6.6

Cosecha y acarreos

0.2

0.2

TOTAL

45.0

7.5

FUENTE: Secretaría de Agricultura y Recursos Hidráulicos. Representación general en el estado de Tamaulipas, zona norte. Jefatura de distrito de riego No. 25, bajo río Bravo. Departamento de Estadística. 
CUADRO 6. Generación de jornales y empleos de los cultivos tradicionales de la región en los distintos períodos.

\begin{tabular}{|c|c|c|c|c|}
\hline \multirow[b]{2}{*}{$\begin{array}{l}\text { Cultivos y } \\
\text { períodos }\end{array}$} & \multicolumn{2}{|c|}{ Generación de Jomales } & \multicolumn{2}{|c|}{ Generación de Empleos } \\
\hline & $\begin{array}{l}\text { Jomales } \\
\text { generados }\end{array}$ & $\begin{array}{l}\% \text { Variación } \\
\text { respecto a } \\
1950-1960\end{array}$ & $\begin{array}{l}\text { Empleos } \\
\text { generados }\end{array}$ & $\begin{array}{l}\% \text { Variación } \\
\text { respecto a } \\
1950-1960\end{array}$ \\
\hline \multicolumn{5}{|l|}{ Algodón } \\
\hline $1950-1960$ & $22,000,000^{1}$ & 100.0 & 130,000 & 100.0 \\
\hline \multicolumn{5}{|l|}{ Maíz } \\
\hline $1960-1970$ & $6,700,0001$ & -69.4 & 30,000 & -77.0 \\
\hline \multicolumn{5}{|l|}{ Sorgo } \\
\hline $1970-1980$ & $1^{\prime} 213,500^{2}$ & -94.1 & 7,291 & -94.6 \\
\hline
\end{tabular}

NOTAS: 1 Se considera que un "pizcador" trabaja un promedio de 12 horas diarias, y que la época de pizca dura en total 45 días, mismos que los pizcadores trabajan en forma continua.

2 Se considera la superficie total por número de jornales por hectáreas y se divide entre 180 , que representa el ciclo vegetativo del sorgo, desde su siembra hasta su cosecha. 
Es decir, con la sustitución de algodón por maíz en el período 1960-1970 sólo se generaba un $23 \%$ de los jornales que en la década anterior (1950-1960) se gencraban. Posteriormente, durante los años setentas, cuando viene a predominar el sorgo en sustitución del maíz, sólo se llegó a generar el $5.6 \%$ de los jornales que en los años cincuenta se generaban (figura 3 ).

La existencia de una agricultura no diversificada agrava los problemas de desempleo de la población campesina, y en el caso concreto de la región que comprende este estudio, tenemos que entre el maíz y sorgo se cubre el $98 \%$ de la superficie total sembrada. Es decir, no existe diversificación de cultivos.

En cuanto a la distribución de estos cultivos por tipo de productor, se tiene que el sorgo es un cultivo meramente comercial cuya producción se genera casi en su totalidad por los grandes agricultores que, además de concentrar la maquinaria, poseen recursos para el financiamiento de su actividad, mientras que el maíz se produce básicamente en predios ejidales y algunos minifundios. Las razones por las que se ha dado este tipo de especialización es que los ejidatarios y minifundistas sólo poseen, bajo sus distintas modalidades, los pedazos de tierra, pero carecen en un alto porcentaje, de recursos económicos para autofinanciarse la adquisición de insumos; igualmente carecen de maquinaria o de recursos para financiar labores de maquila, por lo que tienen gran dependencia del crédito que concede la banca oficial (Banrural), que a través de distintos mecanismos estimula la siembra del maíz.

Entre otros, los incentivos para el cultivo del maíz son: el crédito blando con tasas de interés de un $50 \%$, más bajas que las que se imponen al sorgo, precios de garantía más atractivos, y menores restricciones en cuanto al seguro agrícola y la venta de su cosecha. Estas medidas forman parte de una política definida por el gobierno federal en materia de política agrícola, con el propósito de fomentar la producción de alimentos básicos en busca de la autosuficiencia alimentaria.

Cabe agregar que este tipo de productores (ejidatarios y minifundistas) son los únicos que efectúan dobles cultivos con siembras de maíz y frijol en ciclos de primavera-verano, períodos en que los riesgos de siniestros - fundamentalmente para el maíz - son muy elevados a consecuencia de los ciclos y vientos huracanados que durante ese período acotan en la región. No obstante estos riesgos y problemas, los pequeños campesinos persisten en la siembra de este cultivo como una forma de lograr ingresos durante esa, aunque con la pérdida de la cosecha cargue el seguro agrícola y que por ello, en la mayoría de los casos, impliquen saldos vencidos en sus estados de cuenta.

El cultivo de primavera-verano no es en realidad más que un "amortiguador" que le permite al campesino obtener algunos pesos para subsistir y 


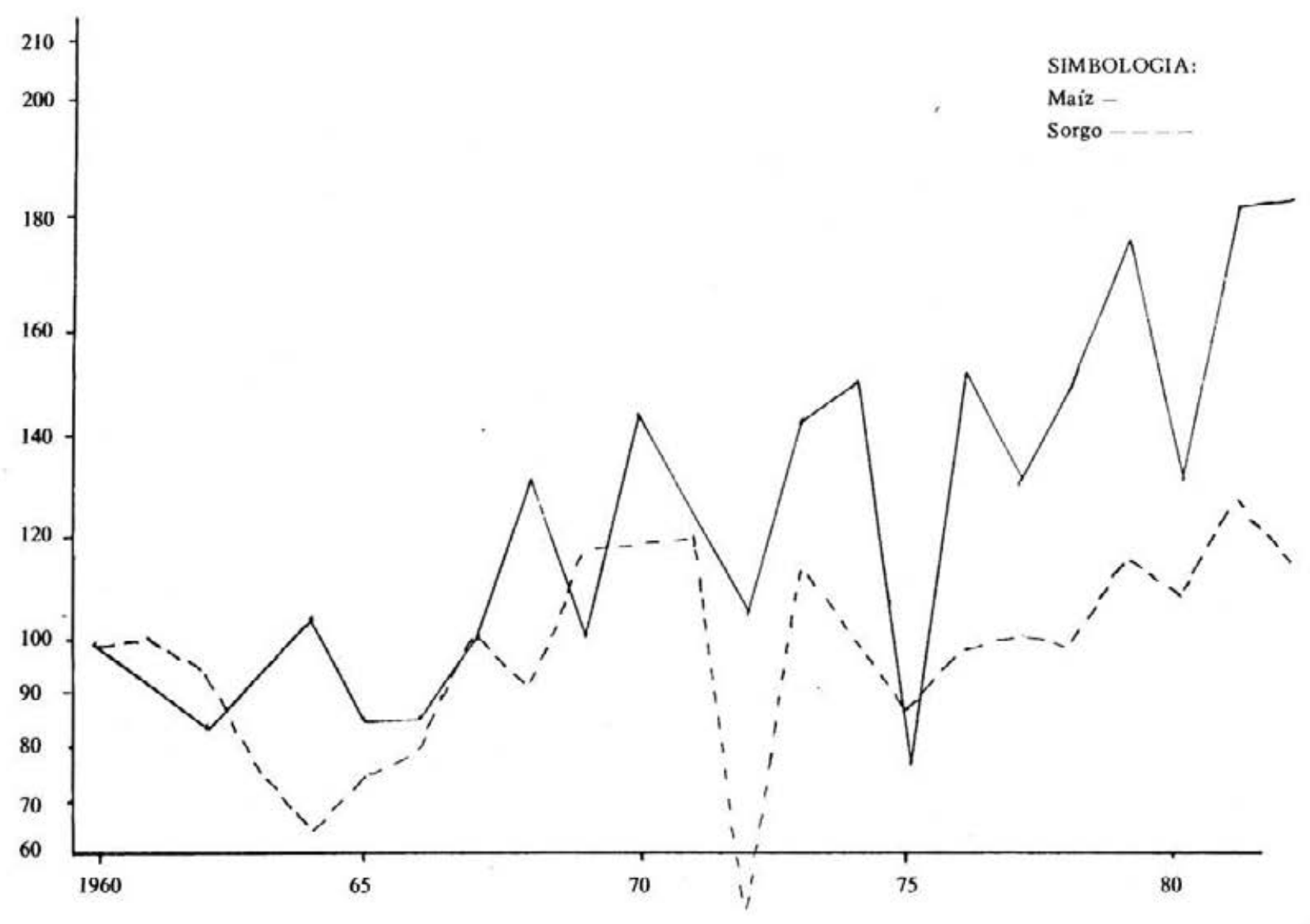

Figura 3. Indice de variación de los rendimientos físicos del maíz y sorgo en los distritos de riego del norte de Tamaulipas. 1960 - 1982. (1960-100). 


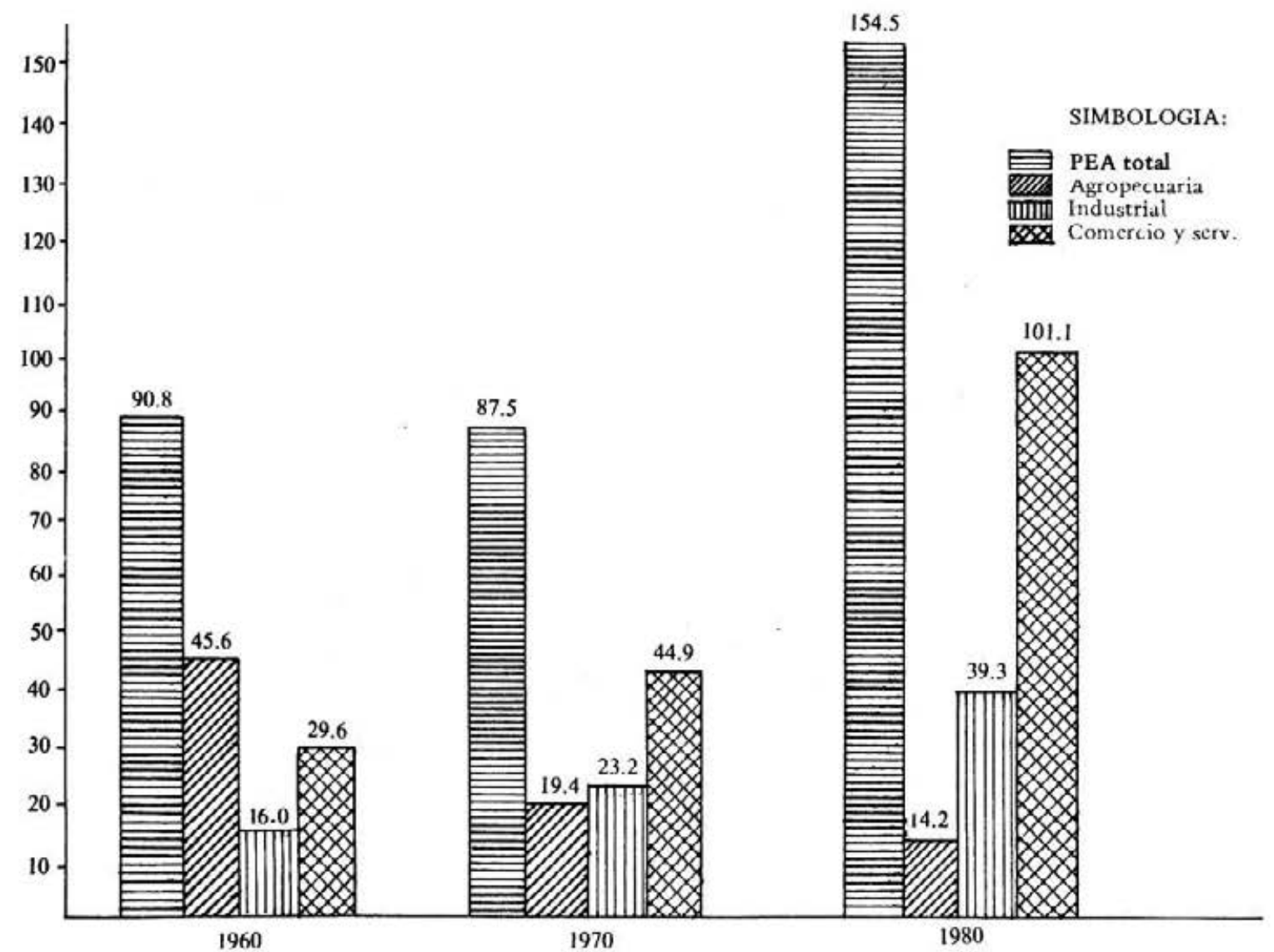

Figura 4. Población económicamente activa por rama de actividad económica en los municipios de Reynosa y Matamoros (miles de personas). 
llegar al próximo ciclo agrícola, donde los resultados de la cosecha le traerán pequeños beneficios y les asegurarán unos cuantos días de jornaleo. 6

La sola modificación en el patrón de cultivos ha contraído la oferta de empleo a un $23 \%$ de lo que fue en los años cincuentas. Pero además, el acelerado proceso de mecanización que se ha venido dando en el campo tamaulipeco ha reducido este porcentaje a un $13.5 \%$. Estas reducciones en la oferta de empleo se han dado no obstante el incremento de la superficie de cultivo, que ha sido de un $50 \%$.

\section{AGRICULTURA MODERNA Y MECANIZACION}

El acelerado proceso de mecanización del sector agrícola se ha dado en todo el país, a consecuencia de una mayor articulación de la economía mexicana a la economía capitalista mundial, como manifestación material de la necesidad que tiene el sistema de la generación de los bienes requeridos para la reproducción de la fuerza de trabajo y la producción de "mercancías", en el contexto de la nueva división internacional del trabajo.7

Como se mencionó con anterioridad, si bien es cierto que el proceso de mecanización ha sido un fenómeno general, en la región que abarca nuestro estudio ha revestido características distintas, tanto en la forma en que el sector agrícola se ha integrado a la economía internacional, como por el peso económico que la presencia de trasnacionales tiene la agricultura de la región. 8

La mecanización de la agricultura de riego en el norte de Tamaulipas, ha sido determinada por la mecánica natural del proceso de trasnacionalización de la agricultura regional. Pero además, para que se diera este proceso ha contribuido una serie de políticas oficiales, entre las que destacan la política de precios a los productos agrícolas, y una política de modernización del sector.

En un intento por incrementar los volúmenes de producción agrícola, se ha incrementado la superficie de cultivo, definiéndose como medio para lograr tal objetivo la intensificación en el uso del capital, lo que ha traído como consecuencia mayor mecanización, es decir, una mayor participación de capital por unidad de tierra y menor participación y peso de la fuerza de trabajo campesina.

\footnotetext{
6 Como un ejidatario mencionaba: "El cultivo de tardio (refiriéndose al ciclo de primavera-verano) lo único que nos asegura es $\mathrm{cl}$ taco, aunque cada vez nos endeuda más".

$7 \mathrm{Al}$ respecto, ver David Barkin y Blanca Suárez, en El fin de la autosuficiencia.

8 Mayor abundancia al respecto se proporciona en el trabajo La agricultura de riego en el norte de Tamaulipas.
} 
Incrementar los niveles de mecanización tenía como objetivo incrementar los niveles de productividad y abatir los costos de producción. De esta manera, lo que se pretendía era crear condiciones para poder mantener a la zaga los precios de los productos agrícolas respecto de los industriales, sin sacrificar los niveles de rentabilidad de los capitales ubicados en el sector agropecuario, lo cual trajo como consecuencia desempleo en el campo y abaratamiento de la mano de obra campesina.

Entre las políticas oficiales orientadas a la modernización del sector agropecuario pueden mencionarse, además de las políticas de precios -tanto generales como de precios de garantía para los productos agrícolas-, las políticas credíticas y de financiamiento al sector agrícola, así como las facilidades fiscales otorgadas a los productores de la región para la importación indiscriminada de maquinaria y equipo agrícola.

La primera (política de precios) ha favorecido más a los productos no básicos que a los productos básicos alimenticios, renglón al que se dedica fundamentalmente la economía campesina; en este aspecto, la producción de productos no básicos es el área en donde se ha especializado la agricultura comercial que, además de concentrar gran parte del capital agrícola, tiene gran acceso a los canales de comercialización a través de las transnacionales (al respecto véase la figura 2 ).

Respecto al segundo tipo de medidas definidas por los gobiernos pasados, se puede afirmar que éstas han permitido la expansión del campo de acción de las empresas transnacionales $y$, asimismo, dichas medidas permiticron que durante el período de crecimiento de la economía mexicana con base en la expansión de la explotación petrolera, en que el poder adquisitivo del peso mexicano con respecto al dólar norteamericano nos era favorable, se importaran grandes volúmenes de maquinaria y equipo, desproporcionado respecto al tamaño de las unidades de producción agrícola. Si bien es cierto que la importación de equipo y maquinaria agrícola efectuada en esos años les rindió a los propietarios, grandes ganancias, ha traído a la región un alto costo social: desocupación y pobreza entre la población campesina, además de una elevada fuga de divisas y gran dependencia tecnológica, que ante la presente crisis monetaria, afecta también a los productores - fundamentalmente a los medianos, que adquirieron equipo durante ese tiempo-, y que ante el incremento de los precios de la refacciones, tienen serias dificultades para su reparación. 9

En este aspecto están sucediendo cosas que son bastante interesantes, como es el caso de que el grueso de las unidades de producción que poseen una alta composición orgánica de capital, se dedican al cultivo del sorgo.

\footnotetext{
${ }_{9}$ Ibidem.
} 
Estas unidades representan el $60 \%$ de la superficie total de riego, y comprenden unidades privadas mayores de veinte hectáreas, algunas de las cuales conforman áreas compactas mayores de cien hectáreas (el límite máximo de la pequeña propiedad) que trabajan bajo la forma de unidades familiares, pero que en realidad no son más que "latifundios familiares", o lo que se ha llamado "neolatifundio".

\section{MIGRACION Y DESARROLLO AGRICOLA}

Lo que hasta aquí se ha expuesto nos permite sugerir que la migración, tanto la que proviene del interior de la república hacia la región fronteriza del norte de México, como la que cruza la frontera hacia Estados Unidos, cstá estrechamente vinculada al proceso histórico de desarrollo del sector agrícola.

Y si tomamos en cuenta que tanto la modificación de los patrones de cultivos como la modernización de las prácticas agrícolas son consecuencia, como scñala David Barkin, de un proceso de internacionalización del sector agrícola, entonces tenemos que la migración no ha sido determinada exclusivamente por factores endógenos de la economía campesina, sino que ha venido siendo fundamentalmente influenciada por este proceso de internacionalización del proceso productivo.

Respecto a la forma en que la internacionalización de la economía mexicana en su integración con Estados Unidos afecta a los movimientos migratorios, Jorge A. Bustamante nos ofrece un buen marco teórico de análisis en el libro Espaldas mojadas. Materia prima para la expansión del capital norteamerican $o^{10}$

Bajo este marco de influericia podemos afirmar que el período de inmigración de población del interior del país a la franja fronteriza del norte de México, se da paralelamente y como respuesta al desarrollo de los grandes distritos agrícolas de riego que estaban teniendo gran impulso en ese perío-

$10 \mathrm{Al}$ respecto, Jorge A. Bustamante señala:

"Se puede concluir que la política de migración del gobierno norteamericano con respecto a mexicanos ha sido una política de abastecimientos de mano de obra para atender los requerimientos de la expansión económica".

Más adelante continúa Bustamante: "la política migratoria de Estados Unidos hacia México dista mucho de haber sido constante. Por el contrario, ha respondido no sólo a los intereses de los dueños del capital que emplean mano de obra mexicana, sino al estado variante de la economía de Estados Unidos". De ahí que no haya sido casual (como el mismo autor continúa diciendo), que las disposiciones legislativas tendientes a restringir más la inmigración se hayan dado en un período de ascendencia de la actividad económica y que por otro lado, la inmigración la hayan estimulado en un período en que padeciera una escasez de mano de obra a consecuencia de la necesidad de destinar los recursos productivos en la economía, como fue el caso del Programa de Braceros convenido entre el gobierno mexicano y el de Estados Unidos en el año de 1942, justamente en pleno desarrollo de la Segunda Guerra Mundial. La iniciativa surgió del gobierno norteamericano. 
do, y justamente en el momento que, impulsado por factores externos, existía un amplio mercado para los productos agropecuarios en el contex to internacional, concretamente en el mercado de Estados Unidos.

Posteriormente, y una vez que gran parte de esa población queda asentada por largos períodos en las áreas rurales o urbanas del norte del país, se inicia el proceso de estancamiento del mercado de trabajo agrícola como consecuencia de la modernización de la agricultura, que traía aparejada la necesidad de la modificación en los propios patrones de cultivos a fin de hacerlas más acordes con el modelo de industrialización de la economía mexicana, determinado en gran medida - como se scñaló antes-por factores externos, y a fin de que respondiera a las modificaciones de los patrones de consumo de una creciente población urbana y a las necesidades del capital trasnacional que se materializara en el contexto de la región, con la presencia de distintas empresas de capital norteamericano.

Es por eso que la migración toma nucvos cursos, orientándose más fuertemente hacia el exterior. Es decir, la población migrante que llegó a las ciudades fronterizas del norte de México busca opciones para emigrar al vecino país e integrarse al mercado de trabajo norteamericano buscando mejores oportunidades de empleo, y los nuevos migrantes provenientes de los estados del interior ya no tienen como perspectiva el establecerse en los estados de la frontera, sino que vienen con la intención clara de emigrar a Estados Unidos.

La modernización de la agricultura en el norte de Tamaulipas no sólo ha afectado a jornaleros agrícolas y migrantes, sino que ha tenido fuertes efectos en un sector de productores agrícolas pequeños, $\mathrm{y}$ ha agudizado la tendencia a la desaparición de la economía campesina con graves consecuencias para el desarrollo económico y social de las zonas urbanas de la región.

La economía campesina ha desempcñado un papel muy importante en la región como elemento amortiguador que da abrigo a la fuerza de trabajo agrícola en las épocas de contracción del mercado laboral, que por las características propias del sector tiene un carácter estacional muy marcado, asegurándole la permanencia en la región de grandes masas de población subempleada que se integran a las labores agrícolas con bajos salarios y sin exigir prestaciones, en el momento en que la agricultura comercial moderna los necesita.

A su vez, esta condición ha sido un elemento vital para la acumulación de capital agrícola en la región y ha permitido la formación de capital en otras áreas de actividad económica vía la transferencia de ganancias.

Por otro lado, la economía campcsina que, como se señala con anterioridad, se sostiene mediante el trabajo familiar, ha sido un elemento muy im- 
portante en la generación de alimentos básicos para la población, abaratando el costo de reproducción de la fuerza de trabajo y garantizándole además, a la agricultura comercial, bajos niveles de salarios para la fuerza de trabajo que contrata.

Asimismo, la propia dinámica de la modernización en la agricultura, consistente en maquinaria e implementos agrícolas sofisticados, requiere de un determinado grado de conocimiento o calificación de los operarios; en este sentido, la economía campesina también garantiza a las grandes unidades de producción agrícola comercial, fuerza de trabajo calificada sin costo alguno, y a la cual también se le puede contratar temporalmente, pagándosele únicamente el tiempo en que es estrictamente necesaria, sin que represente para ello un costo en el renglón de educación, salud u otro tipo de prestaciones a las que legalmente tiene derecho un obrero de una fábrica. Es decir, ha asegurado a los capitales de la región, la reproducción de la fuerza de trabajo sin que implique para ellos mayor costo. Esto ha favorecido a los capitales agrícolas y no agrícolas de la región norte de Tamaulipas, así como a los del otro lado de la frontera, en el sur de Texas, que emplean mano de obra de migrantes mexicanos del norte de Tamaulipas, y a quienes ocupan temporalmente en los campos de cultivo.

Una modalidad de la economía campesina o de las pequeñas unidades de producción agrícola en la región, es que, favorecidas por las condiciones de clima (buenos niveles de precipitación pluvial, con una distribución más o menos regular durante todo el año), se hacía posible la práctica ganadera en pequeña escala o crianza doméstica de animales, de donde obtenían alimentos tales como leche, huevo, queso, y ocasionalmente, carne. Estos productos se destinaban principalmente para autoconsumo, pero en forma regular les generaban algunos excedentes que comercializaban en las áreas geográficas de influencia, suministrando en conjunto una parte importante de la oferta de alimentos de este género entre la población. Esta condición, que permitía una oferta de productos alimenticios más baratos, también favorecía el abatimiento de costo de la fuerza de trabajo, incluso para los centros urbanos de la región y para el establecimiento de plantas agroindustriales con capital de empresas transnacionales.

Para medir la importancia que la economía campesina tuvo en el mercado agrícola regional señalaremos que, en los distritos de riego de la región, un $50 \%$ de los predios revisten este carácter o caen en esta categoría. Esta forma se deriva del hecho de que en la región existen un total aproximado de seis mil doscientos ejidatarios y unos mil minifundistas, que en la mayoría de los casos se dedican al jornaleo agrícola y rentan sus parcelas, pero que viven en el campo y poseían sus pequeñas unidades pecuarias con las características antes mencionadas. 
En total, en la región -hablando de superficies de riego y temporalexisten veinte mil ejidatarios trabajando sus parcelas en forma individual mediante las dotaciones ejidales parcelarias.

El colectivismo en la región es una categoría no común, podríamos decir casi inexistente, y el total de ejidos dentro del distrito de riego que tienen financiamiento de Banrural, trabajan en forma individual. Esto indiscutiblemente los hace más sensibles a las variaciones de la actividad, y la pulverización de los recursos destinados para la explotación de sus ticrras los hace fácil presa del acaparamiento y el rentismo, fenómenos que han proliferado más fuertemente en los últimos años ante la necesidad de los pequeños campesinos de emigrar a la ciudad o a los campos agrícolas de Estados Unidos en busca de trabajo. En este proceso abandonan sus parcelas o las rentan.

Este fenómeno de abandono de parcelas o rentismo de las mismas ha traído como consecuencia, además, que muchas de las unidades de producción denominadas de economía campesina -que tenían como fuente importante de ingresos el jornaleo agrícola-, y la producción a niveles domésticos de diversos productos alimenticios - que jugaban un papel importante en la oferta regional-, hayan desaparecido.

En una investigación efectuada por el autor de este trabajo durante los meses de octubre y noviembre de 1983, y con el auxilio de personas residentes en el valle y conocedores de la región, entre los que se contaban extensionistas de la Secretaría de Agricultura y Recursos Hidráulicos, así como viejos avecindados ejidatarios, algunos de ellos de la región, se llegó a estimar que en los distritos de riego número 25 y 26 , existían aproximadamente unos tres mil "pequeños ranchitos" que poseían, en promedio, unas diez reses por unidad, poseyendo un total aproximado de treinta mil cabezas, lo que representaba una cifra cercana al $40 \%$ de la población de bovinos en los municipios de Matamoros, Reynosa, Valle Hermoso y Río Bravo, y que en total suministraba el $40 \%$ de la demanda de productos de este origen como son leche, carne y queso.

La importancia que cstas unidades de producción tenían en cuanto a la participación en la producción de este tipo de alimentos, puede evidenciarse incluso a través de las estadísticas del sector, que muestran cómo en el periodo anterior a 1970 se registraron los niveles más altos de producción, y que más o menos sc mantuvo estable, pero iniciándose a principios de los setenta (1972) la producción de alimentos de origen pecuario se desploma fuertemente.

El desplome de la producción de estos bienes alimenticios en la región coincide con la presencia de los consorcios transnacionales comercializadores de grano, que por un lado compiten con la ganadería regional a escala no tec- 
nificada al destinar recursos para el financiamiento de cultivos de alta rentabilidad con la introducción de maquinaria que requería la explotación a niveles extensivos y al aumentar la especialización de la producción hacia el sorgo, pero para la comercialización como producto final. Es decir, coadyuva al desarrollo especializado del sector, favoreciendo la agricultura comercial. Por otro lado, estas empresas, (las transnacionales) en gran parte se dedican a la compra de granos para la producción de alimentos balanceados, pero la transformación la efectúan en otras regiones. Es decir, las transnacionales captan mediante contratos de compra-venta la producción de granos, misma que es enviada a los centros donde tienen sus plantas de transformación, ya sea la región del Bajío o en el centro del país, c incluso en algunas plantas ubicadas en los estados de Arizona y Texas. Esto definitivamente ha representado una situación muy desventajosa para la actividad pecuaria regional, que está sufriendo una constante extracción de insumos y no le permite la posibilidad de desarrollarse.

Las consecuencias podrán verse a través de los flujos de población que migra de los poblados rurales de la región a los centros urbanos de Matamoros o Reynosa, pasando a engrosar los ya amplios cinturones de población marginada que vive de dedicarse a labores que en ningún momento le garantizan niveles de ingreso que le permitan vivir en condiciones decorosas, sino que vive en condiciones infrahumanas, con graves problemas de atención en cuanto a condiciones de salud, educación y alimentación se refiere.

Esto puede explicarse además por la disminución real de la población rural en Matamoros y Reynosa, principales municipios en el área de estudio que comprende este trabajo. En el cuadro 7 se puede observar que la población rural que para el municipio de Matamoros arrojó el VII Censo General de Población en el año de 1960, fue de aproximadamente 56 mil habitantes, misma que se redujo para el año de 1970 a 42 mil, lo que representó una disminución promedio anual de $1.4 \%$ aproximadamente (ver cuadro 8 ). Si analizamos esta tendencia por décadas, tenemos que en el período de 1950 a 1960 el decremento se dio a razón del uno por ciento en promedio anual, mientras que cn la década de los sesentas (1960-1970) la disminución se dio a razón del $1.8 \%$.

Para el caso de Reynosa existen algunos elementos significativos, como por ejemplo, durante el período de los sesentas, la población rural que albergaba el municipio se incrementó en un 30\% aproximadamente, pero en el período de 1960 a 1970 se registró un decremento mayor de $70 \%$. Es decir, las variaciones globales durante los dos períodos reflejan que durante la primera década la población creció a razón del $3 \%$ anual, mientras que en el período posterior (1970) decreció a razón del $7 \%$ promedio anual. 
CUADRO 7. Distribución de la población urbana y rural de los principales municipios fronterizos del norte de Tamaulipas.

\begin{tabular}{|c|c|c|c|c|c|c|}
\hline ANO Y CONCEPTO & \multicolumn{3}{|c|}{ MATAMOROS } & \multicolumn{3}{|c|}{ REYNOSA } \\
\hline & Abs. & & Rel. & Abs. & & Rel. \\
\hline \multicolumn{7}{|l|}{1950} \\
\hline Pob. total & 128 & 347 & 100 & 69 & 428 & 100 \\
\hline Urbana & 72 & 353 & 56 & 38 & 717 & 5 \\
\hline Rural & 55 & 994 & 44 & 30 & 711 & \\
\hline 1960 & & 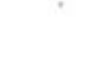 & & & & \\
\hline Pob. total & 143 & 043 & 100 & 134 & 869 & 10 \\
\hline Urbana & 92 & 327 & 64 & 91 & 640 & \\
\hline Rural & 50 & 716 & 36 & 43 & 229 & 3 \\
\hline \multicolumn{7}{|l|}{1970} \\
\hline Pob total & 186 & 164 & 100 & 150 & 786 & 100 \\
\hline Urbana & 144 & 135 & 77 & 137 & 383 & \\
\hline Rural & 42 & 029 & 23 & 13 & 403 & \\
\hline
\end{tabular}

FUENTE: Censos Generales de Población 1950, 1960 y 1970. Dirección General de Estadística.Se. cretaría de Industria y Comercio.

CUADRO 8. Tasas de variación media anual de la población rural en los municipios de Matamoros y Reynosa. 1950 - 1970.

\begin{tabular}{lcc}
\hline PERIODOS & MATAMOROS & REYNOSA \\
\hline $1950-1960$ & $-1.0 \%$ & $4.3 \%$ \\
$1960-1970$ & $-1.8 \%$ & $-7.0 \%$ \\
$1950-1970$ & $-2.4 \%$ & $-1.5 \%$ \\
\hline
\end{tabular}

FUENTE: Elaborado con base en el cuadro 2. 
Por otro lado, si atendemos la información referente a la población económicamente activa por rama de actividad económica, tenemos que en los mismos municipios tambićn se registraron, durante el período de 1960 a 1980 , sustanciales variaciones.

Así, tenemos que la PEA del sector agropecuario en el municipio de Matamoros que en el año de 1980 alcanzó la suma de más de veintidós mil personas, para el año de 1980 sólo estaba conformada por nueve mil quinientos; es decir, se redujo en un $57 \%$, a lo que le correspondió una tasa promedio anual de decrecimiento del $2.9 \%$ durante todo el período (cuadros 9 y 10 ).

Para el caso del municipio de Reynosa, la disminución fue aún mayor, con una tasa de $4 \%$ anual durante los veinte años, lo que implicó que la PEA del sector hubiera disminuido de veintitrés mil habitantes que la integraban en el año de 1960, a cuatro mil seiscientos cincuenta en el año de 1980.

Para esta investigación, el flujo migratorio del campo a las ciudades en busca de empleo pudo constatarse, además, mediante una encuesta que durante los meses de noviembre y diciembre de 1983 se efectuó con personas que transitaban por las carreteras del valle. El total de los entrevistados tenía extracción rural, ya que eran campesinos o hijos de campesinos. El $90 \%$ de ellos vivía aún en el campo o poblados rurales. De éstos, el $60 \%$ iba con destino a alguna de las dos principales ciudades de la región (Matamoros y Reynosa) en busca de trabajo. Cuando se les preguntó respecto al tipo de trabajo que pretendían desempeñar, todos respondieron que "en lo que fuera". Cuando se les insistía respecto a la opción más viable que ellos tenían para trabajar, el $41 \%$ de ellos respondieron que de jardineros en las zonas residenciales, $27 \%$ dijeron que lavando carros, $12 \%$ dijeron que en alguna gasolinera o estación de servicios y el $20 \%$ restante, señaló que como peones o albañiles en la industria de la construcción.

Cuando se les preguntó la causa por la que ellos emigraban a la ciudad, el $100 \%$ señaló que era la carencia de trabajo en el campo, agregando gran número de ellos que las unidades parcelarias eran tan pequñas que no era posible el sostenimiento de toda la familia, por lo que se veían obligados a buscar nuevas posibilidades de empleo.

Otra de las causas de la emigración, aunque debido a las características de esta encuesta no se pudo detectar un factor que nos permitiera medirla, es la provocada por la necesidad de servicios a los que no se tiene acceso en los poblados rurales, como son educación, centros de salud u otros. Este tipo de migración comúnmente se hace en forma definitiva y a nivel familiar, pero además, casi es exclusiva de un tipo de campesinos con el nivel de vida superior al del campesino pobre; es decir, el campesino medio. Este tipo de migración tuvo gran importancia en los años sesenta y principios de los seten- 
CUADRO 9. Distribución de la PEA por sector de actividad de los principales municipios fronterizos del norte de Tamaulipas.

\begin{tabular}{lrrrrrrr}
\hline AÑO Y SECTOR & \multicolumn{3}{c}{ MATAMOROS } & \multicolumn{3}{c}{ REYNOSA } \\
& Abs. & & Rel. & Abs. & Rel. \\
\hline 1960 & 45 & 882 & 100.0 & 44 & 925 & 100.0 \\
$\quad$ PEA total & 22 & 456 & 49.0 & 23 & 096 & 52.0 \\
$\quad \begin{array}{l}\text { Agropecuario } \\
\text { Industrial }\end{array}$ & 7 & 553 & 16.0 & 8 & 526 & 18.0 \\
$\begin{array}{l}\text { Comercio y } \\
\text { Servicios }\end{array}$ & 16 & 033 & 35.0 & 13 & 526 & 30.0
\end{tabular}

1970

$\begin{array}{lrrrrrr}\text { PEA total } & 49 & 467 & 100.0 & 38 & 023 & 100.0 \\ \text { Agropecuario } & 13 & 311 & 27.0 & 6 & 122 & 16.0 \\ \text { Industrial } & 10 & 378 & 20.0 & 12 & 783 & 34.0 \\ \begin{array}{l}\text { Comercio y } \\ \text { Servicios }\end{array} & 25 & 778 & 53.0 & 19 & 127 & 50.0\end{array}$

1980

\begin{tabular}{lrrrrrr} 
PEA total & 86 & 470 & 100.0 & 68 & 069 & 100.0 \\
Agropecuario & 9 & 517 & 11.0 & 4 & 650 & 7.0 \\
$\begin{array}{l}\text { Industrial } \\
\begin{array}{l}\text { Comercio y } \\
\text { Servicios }\end{array}\end{array}$ & 21 & 404 & 24.0 & 17 & 892 & 26.0 \\
& 55 & 549 & 65.0 & 45 & 527 & 67.0 \\
\hline
\end{tabular}

FUENTE: Censos Generales de Población 1960 y 1970. Dirección General de Estadística, Censo Ge. neral de Población 1980. Instituto Nacional de Estadística, Geografía e Informática. Secretaría de Programación y Presupuesto. 
CUADRO 10. Tasas de variación media anual de la población económicamente activa del sector agropecuario en los municipios de Matamoros y Reynosa.

\section{PERIODO}

$1960-1970$

$\begin{array}{rrr}\text { Sector I } & -4.2 \% & -7.4 \% \\ \text { II } & 3.7 \% & 5.4 \% \\ \text { III } & 6.1 \% & 4.1 \%\end{array}$

$1970-1980$

Sector I

II

III
$-3.1 \%$

$10.6 \%$

$11.5 \%$
$-2.4 \%$

$4.0 \%$

$13.8 \%$

$1960-1980$

Sector I

II

III
$-3.5 \%$

$9.2 \%$

$12.3 \%$
$-4.0 \%$

$5.8 \%$

$11.8 \%$

FUENTE: Elaborado con base en el cuadro 5. Variaciones porcentuales de la PEA.

tas, en que los altos niveles de rentabilidad de la tierra le permitían al campe. sino medio obtener niveles de vida característicos de la población urbana.

\section{CONCLUSIONES}

Como se menciona con anterioridad, el proceso de modernización de la agricultura mexicana ha tenido graves efectos para la economía campesina y ha hecho a la agricultura más sensible y dependiente de la actividad industrial para el suministro tanto de sus insumos como de los bienes de capital, muchos de ellos de origen extranjero, razón por la cual la presente crisis económica y la modificación en los tipos de cambio del peso mexicano con respecto al dólar estadounidense, ha provocado que la práctica agrícola sólo sea rentable en términos económicos, mediante la explotación de grandes exten- 
siones de tierras, lo que ha sido posible ya que el proceso de descomposición de la economía campesina, provocada -como se explicó- por la propia dinámica de modernización e internacionalización de la agricultura, ha obligado al campesino a abandonar su parcela, haciendo la práctica del rentismo de tierras un fenómeno generalizado.

La sustitución de cultivos con un uso intesivo de mano de obra por otros cultivos de uso intensivo de capital, la inexistencia de una agricultura diversificada, y el acelerado proceso de mecanización de las labores agrícolas, han provocado que esta actividad en la región requiera cada vez de menos fuerza de trabajo campesina y que ésta tenga una menor participación en el valor de producción agrícola generado.

Como contraparte, el trabajo de los obreros del sector industrial ha venido teniendo una mayor participación a través de los insumos agrícolas de origen industrial Este proceso tiende a acentuarse debido a la tendencia creciente de la composición orgánica de los capitales de la agricultura.

El hecho de que la actividad agrícola dependa en mayor proporción de los insumos industriales, es característico de la agricultura de los países altamente industrializados, donde los niveles de tecnificación se han traducido en mayor productividad tanto de la fuerza de trabajo, como de los recursos productivos (fundamentalmente agua y tierra), pero en el caso de la región que abarca nuestro estudio, la mecanización ha provocado mayor productividad de la fuerza de trabajo, mas no ha provocado mayor productividad de los otros recursos productivos a los que se hace referencia líneas arriba.

Lo anterior nos permite afirmar que el modelo de mecanización adoptado en la región, lejos de haber favorecido el desarrollo de la misma, ha provocado una agudización de los niveles de pobreza y ha acentuado los niveles de concentración del ingreso en manos de quienes han podido, mediante diversas formas, acumular tierra y aprovechar, mediante el uso de ésta, la infraestructura y otros recursos financieros canalizados al campo por el sector público.

Finalmente, y a manera de conclusión, podemos decir que el modelo de crecimiento del sector agrícola en la región ha causado la expulsión masiva de campesinos, al no garantizarles ya los medios suficientes para subsistir. Los expulsa arrojándolos a los centros urbanos donde tampoco pueden encontrar acomodo dentro del mercado de trabajo mediante el empleo formal, lo que se ha traducido en una creciente terciarización de la economía de estos municipios, que está conformada en gran medida por fuerza de trabajo libre, subempleada, que desempeña labores sin poder establecer relaciones laborales formales; es decir, es un grupo de población marginal que cada vez crece en mayor proporción, alimentada por los constantes flujos de población campesina que migra del campo a la ciudad. 


\section{BIBLIOGRAFIA}

ABRE Abercrombie, R. S. "Mecanización agrícola y ocupación en America Latina" en E. Feder, compilador, La lucha de clases en el campo.

ABURTO, Horacio. "El maíz: Producción, consumo y política de precios". En Maíz, política institu. cional y crisis agricola. Centro de Investigaciones para el desarrollo rural. México, D.F., Editorial Nueva Imágen, 1979, pp 131-169.

BARKIN, David y Blanca Suárez. El fin del principio. Centro de Ecodesarrollo. Editorial Oçéano. México, D.F. 1983.

BOLTVINIK, Julio. Estrategia de desarrollo rural, economía campesina e innovación tecnológica en México. Comercio Exterior, Vol. No. 7. México, julio 1976.

BUSTAMANTE, F. Jorge A. Espaldas mojadas: materia prima para la expansión del capital norteamericano. El Colegio de México.

CISNEROS Rodríguez Manuel. Características de la agricultura mexicana y proyecciones de la oferta de productos agropecuarios. 1976-1982. Banco de México.

CONTRERAS, José Luis. La agricultura de riego eñ el norte de Tamaulipas. Trabajo en claboración.

FLIT STERN, Isaías. "Tecnologías apropiadas o manejos apropiados de las tecnologías: el caso de la agroindustria", en: Desarrollo agroindustrial. ..

GASCON MERCADO, José. "La industria ejidal: Alcances y limitaciones en: Desarrollo agroindustrial. ..

JUSIDMAN de Bialostoski, Clara y Ramón Narváez Quintero, La agroindustira como una opción al problema del desempleo y subempleo en el campo en Desarrollo agroindustrial, tecnología y empleo. Documentos de trabajo, para el desarrollo agroindustrial. Vol. No. 3, Coordinación General de Desarrollo Agroindustrial. Secretaría de Agricultura y Recursos Hidráulicos. México, D.F., 1982.

LEFF Zimmerman, Enrique. "Agroindustria y Desarrollo”, en: Desarrollo agroindustrial. . .

MEZZERA, Jaime. "Diagnóstico y estrategias de empleo y necesidades básicas", en Desarrollo agroindustrial. ..

ORIVE Aiba, Adolfo. La irrigación en México. Editorial Grijalbo. México, 1970 ,

PELLIZER de Alcaraz, Irma. "El Programa Nacional de Ciencia y Tecnología (1978-1982); en Desarollo agroindustrial tecnología y empleo. Documentos de trabajo para el desarrollo agroindus. trial, Vol. No. 3, Coordinación General de Desartollo Agroindustrial, Secretaria de Agricultura y Recursos Hidráulicos, México D.F., 1982.

PEREZ, Villaseñor Javier. "El impacto de la educación y la investigación en el desarrollo tecnológico agroindustrial" en : Desarrollo agroindustrial. ...

RAMA, D. Ruth. Transnacionalización de la agroindustria mexicana y difisión tecnológica en: Desa. rrollo agroindustrial. .

SECRETARIA DE AGRICULTURA Y RECURSOS HIDRAULICOS. Informe de labores V años.

SECRETARIA DE PROGRAMACION Y PRESUPUESTO. Manual de estadisticas bisicas. Tamaulipas, Censo de Población y Vivienda del Estado de Tamaulipas.

WAISSBLUTH Subeeman, Mario. "Agroindustria, tecnología doméstica y empleo" en: Desarrollo agroindustrial... 